\title{
Utility of Endotracheal Tube Cuff Pressure Monitoring in Mechanically Ventilated (MV) Children in Preventing Post-extubation Stridor (PES)
}

Farhan Shaikh ${ }^{1} \odot$, Yeshwanth R Janaapureddy ${ }^{\circledR}$, Shashwat Mohanty ${ }^{\oplus}$, Preetham K Reddy ${ }^{4}$, Kapil Sachane ${ }^{5}$,

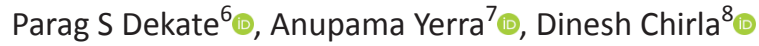

\begin{abstract}
Objective: To study if protocolized monitoring of endotracheal tube (ETT) cuff pressure every 6 hours is better than adjusting endotracheal tube cuff inflation by the only bedside clinical assessment.

Materials and methods: This was a single-center prospective randomized controlled study done between July 1, 2017 and March 31, 2019. Children between 1 month and 18 years, intubated with cuffed ETT by our trained doctors were included. After obtaining consent, patients were randomized into two groups, standard group (SG) and cuff pressure monitoring group (MG). Sample size was calculated with 80 patients in each group with a power of $80 \%$, significance level (alpha 0.05 and beta 0.2 ). In the SG, ETT cuff inflation was adjusted by clinical assessment (bedside minimal leak technique and monitoring the percentage of leak displayed on ventilator display) at 6 hours interval. In the MG, cuff pressures were monitored by the device every 6 hours to maintain between 20 and $25 \mathrm{~mm} \mathrm{Hg}$.

Results: Out of 543 mechanically ventilated children during the study period, 266 were eligible and randomized for study. During the study, 89 patients died and 17 were left against medical advice, leaving 80 patients in each group. Incidence of post-extubation stridor (PES), re-intubation rate, ventilator-associated pneumonia (VAP) rate, ventilator days, and length of pediatric intensive care unit (PICU) stay were analyzed and found no advantage of protocolized monitoring of cuff pressures in the reduction of any of the above variables.

Conclusion: Our findings if confirmed by large multicentric studies can bring an end to routine ETT cuff pressure measurements and emphasize more on clinical assessment. Clinical trial registry (CTRI/2019/05/019098).

Keywords: Cuff pressure, Endotracheal tube, Monitoring, Post-extubation stridor.

Indian Journal of Critical Care Medicine (2021): 10.5005/jp-journals-10071-23737
\end{abstract}

\section{INTRODUCTION}

Children with critical illness frequently require endotracheal intubation to maintain the airway. Post-extubation stridor (PES) is a well-known complication of endotracheal intubation. Earlier post-extubation hoarseness was reported in children mainly. ${ }^{1}$ PES results in prolonged mechanical ventilation days and intensive care unit stay. ${ }^{2}$ PES occurs in up to $30 \%$ of extubations in PICUs, resulting in reintubation up to $6 \% .^{3-5}$ Approximately a quarter of all failed extubations in PICU are due to PES. ${ }^{6}$ In the past, cuffed endotracheal tube usage in younger children was avoided due to the risk of subglottic airway edema., ${ }^{7,8}$ Deakers et al. showed that postextubation stridor is not different among cuffed and uncuffed ETT in children. ${ }^{4}$ From the year 2005, Pediatric Advanced Life support (PALS) from the American Heart Institute and the International Liaison Committee on Resuscitation have changed their recommendations in favor of using cuffed endotracheal tubes for all ages in children. ${ }^{9,10}$ Ensuring adequate inflation of endotracheal tube cuff is important. High cuff pressures result in airway edema, impaired tracheal blood flow, and subglottic stenosis. ${ }^{11}$ On the other hand, low cuff pressures can result in a significant leak around ETT, inadequate ventilation, and micro-aspiration. ${ }^{12}$ The ETT cuff pressure can be monitored by directly measuring the cuff pressure by various devices. However, at the bedside, the adequacy of ETT cuff pressure can also be indirectly assessed by various means. For example, minimal leak technique where the leak is heard by auscultating over the trachea and allowing leak sound only at the peak inspiratory pressure. ${ }^{13}$ However, Mhanna et al. study in a

\begin{abstract}
${ }^{1-8}$ Department of Pediatric Intensive Care Unit, Rainbow Children's Hospital, Hyderabad, Telangana, India

Corresponding Author: Yeshwanth R Janaapureddy, Department of Pediatric Intensive Care Unit, Rainbow Children's Hospital, Hyderabad, Telangana, India, Phone: +91 9440912131, e-mail:yashu198@yahoo.co.in How to cite this article: Shaikh F, Janaapureddy YR, Mohanty S, Reddy PK, Sachane K, Dekate PS, et al. Utility of Endotracheal Tube Cuff Pressure Monitoring in Mechanically Ventilated (MV) Children in Preventing Post-extubation Stridor (PES). Indian J Crit Care Med 2021;25(2):181-184.
\end{abstract}

Source of support: Nil

Conflict of interest: None

pediatric ICU found the "minimum leak" test or cuff-leak test to be unreliable in children below 7 years of age..$^{14}$

Here, we sought to determine whether measuring ETT cuff pressure at regular intervals in a protocolized manner would decrease the incidence of post-extubation stridor when compared to performing bedside clinical assessment for the leak (minimal leak test).

\section{Materials and Methods}

This was a single-center prospective randomized controlled trial done between July 1, 2017 and March 31, 2019 after approval from Rainbow Children's Hospital's ethics committee.

o Jaypee Brothers Medical Publishers. 2021 Open Access This article is distributed under the terms of the Creative Commons Attribution 4.0 International License (https://creativecommons.org/licenses/by-nc/4.0/), which permits unrestricted use, distribution, and non-commercial reproduction in any medium, provided you give appropriate credit to the original author(s) and the source, provide a link to the Creative Commons license, and indicate if changes were made. The Creative Commons Public Domain Dedication waiver (http://creativecommons.org/publicdomain/zero/1.0/) applies to the data made available in this article, unless otherwise stated. 
Children between 1 month and 18 years, intubated with cuffed ETT by our trained doctors were included. Infants born prematurely were corrected to gestational age. Exclusion criteria were age group $<1$ month and $>18$ years, patients who were ventilated for upper airway obstruction/upper airway anomalies, patients who were already intubated with an uncuffed endotracheal tube, who died before extubation, and who were intubated in outside hospitals by their team of physicians. The size of the cuffed ETT was as per the modified Cole formula [ETT inner diameter $=$ (age in years/4) +3.5$].^{4,5,8}$

Two types of ETT are included in the study-Teleflex ${ }^{\circledR}$ Medical, INC Rusch ${ }^{\circledast}$ sterile cuffed ETT, and Smiths ${ }^{\circledast}$ siliconized PVC, Portex ${ }^{\circledast}$. Both types of ETT used in the study are PVC based siliconized ETT. During the early phase of our study, there was a short supply of micro-cuff endotracheal tubes in our unit. Hence, when they became available after the commencement of our study, we decided not to use them for intubation until enrollment of patients under our study was completed. This decision was made because the dynamics of micro-cuff ETT would be different and would have affected the outcomes of our study.

Air was used to inflate the cuff. Patients were randomized by a sealed envelope system. Once consent has been obtained, a sealed envelope is opened after intubation, and the patient is allocated into either of the two groups, standard group (SG) and cuff pressure monitoring (MG) group. It is a non-blinded RCT and the authors of this study were part of treating PICU where patients were admitted.

Our study is the first prospective randomized controlled study in the pediatric age group on assessing the use of ETT cuff pressures to prevent PES. Based on the reduction in PES before and after monitoring cuff leak pressures in a previous study, ${ }^{15}$ we calculated sample size which is approximately 80 patients in each group with power of $80 \%$, significance level (alpha 0.05 and beta 0.2 ). The sample size was calculated with 'statistical software R'.

In SG, the leak around ETT was assessed by the "minimal leak" technique where we auscultated over the trachea of intubated patients and inflated the ETT cuff with air until a leak sound is heard only at peak inspiration. Additionally, we also monitored the "leak" displayed on the ventilator screen and a leak of up to $10 \%$ was accepted if the child was hemodynamically stable and ventilated optimally. This procedure was repeated every six hours.

In MG, cuff pressures were monitored by a device (Portex ${ }^{\oplus}$ company manometer) every 6 hours to maintain between 20 and $25 \mathrm{~mm} \mathrm{Hg}$. Current AHA recommendations for maintaining cuff pressure at $\leq 20-25 \mathrm{~cm} \mathrm{H}_{2} \mathrm{O}$. But Tobias still recommends 20-30 $\mathrm{cm} \mathrm{H}_{2} \mathrm{O}$ cuff pressure as the rule until evidence delineates a more appropriate range. ${ }^{16,17}$ Rationale of these recommendations is to keep the cuff pressures below normal capillary pressure of $30 \mathrm{~mm} \mathrm{Hg}$ to prevent ischemic injury of the laryngeal mucosa. ${ }^{18}$ After extubation, patients in both arms were observed for the incidence of PES, ventilator-associated pneumonia (VAP), and the total duration of ventilator support.

Studies in the past considered need for adrenaline nebulization in the post-extubation period as PES marker ${ }^{4,5}$ and hence in our study, children who required adrenaline nebulizations within 24 hours of extubation for upper airway obstruction were defined as having "post-extubation stridor" (PES). The need for adrenaline nebulization was determined based on the clinical judgment of the presence of upper airway obstruction features.

\section{Results}

A total of 2102 children were admitted to our PICU during the study period. Of these, 543 children were mechanically ventilated. Out of 543 ventilated children, 266 were eligible and randomized for study. During the study, 89 patients died and 17 patients left against medical advice, leaving 80 patients in each group (Fig. 1).

There was no difference in median age $(p=0.728)$, or weight $(p=0.675)$, or gender $(p=0.341)$, or diagnostic categories $(p=0.858)$ between both the groups.

Seven children developed stridor in SG and the average duration of stridor was 5.57 hours whereas five children developed stridor in MG with an average duration of stridor was 5.8 hours. There was no statistical difference in the occurrence of PES between SG and MG ( $p=0.551)$ including the duration of stridor $(p=0.85)$ (Table 1). There were 44 (27.5\%) patients who were below one year age group and 1 (2.27\%) infant developed PES.

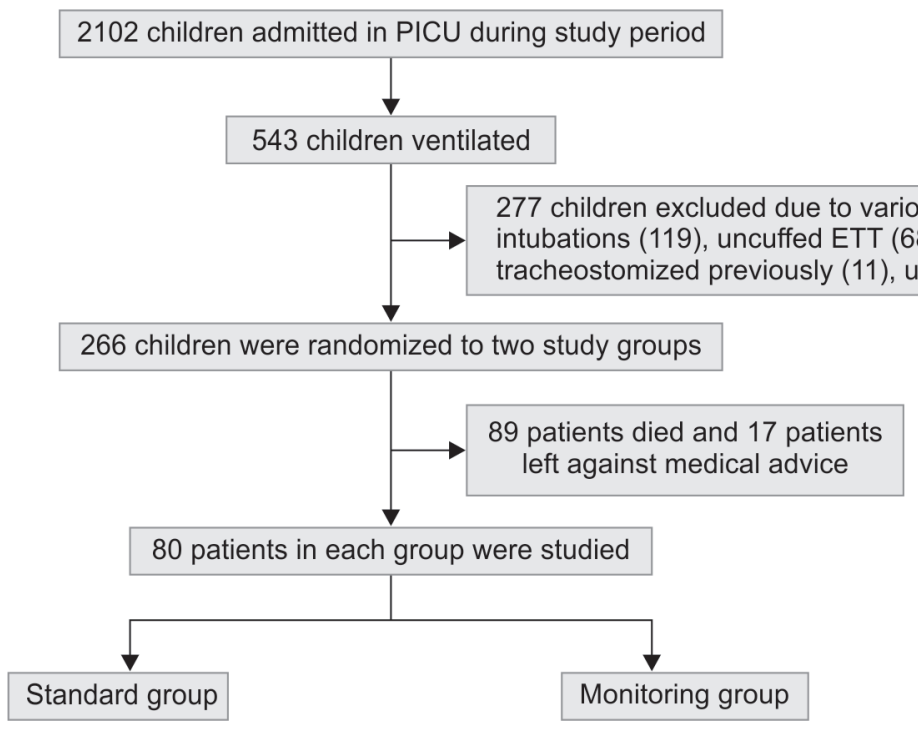

Fig. 1: Patient's disposition 
Table 1: Post-extubation stridor and re-intubation rates in study

\begin{tabular}{llll}
\hline & $\begin{array}{l}\text { Standard care } \\
\text { group }(n=80)\end{array}$ & \multicolumn{2}{l}{ Monitoring care } \\
group $(n=80)$ & $p$-value \\
\hline Post-extubation stridor & $7(8.75 \%)$ & $5(6.25 \%)$ & 0.551 \\
Re-intubation rate & $8(10 \%)$ & $2(2.5 \%)$ & 0.051 \\
Average stridor duration & $5.57 \mathrm{hrs}$ & $5.8 \mathrm{hrs}$ & 0.85 \\
\hline
\end{tabular}

The average leak in SG was $5.4 \%$ whereas it was $4.7 \%$ in MG. There was no statistical significance between the leak in both groups ( $p=0.07$ ). A leak of more than $20 \%$ around the ETT tube was seen in three patients in SG and four patients in MG. All seven children underwent ETT tube change and none developed PES. Average cuff pressures were $21.5 \mathrm{~mm} \mathrm{Hg}$ in MG and average cuff pressures in the PES group were $21.4 \mathrm{~mm} \mathrm{Hg}$. Thus the cuff pressures were almost the same in MG whether they developed PES or not.

Various other parameters were analyzed. The total VAP rate in the study population was $11.78 / 1000$ ventilator days with the VAP rate of SG cohort-10.56/1000 ventilator days and MG cohort were $13 / 1000$ ventilator days. There was no difference in the incidence of VAP in SG and MG groups ( $p=0.468$ ). There was no difference in the duration of mechanical ventilation before extubation between the two groups (mean ventilator days in the standard group was 4.8 days vs 3.6 days in the monitoring group $p=0.066$ ). Eight children required reintubation in SG and two children in MG. There was no difference in the incidence of reintubation between both groups $(p=0.051)$. Reintubation due to PES was also similar $(p=0.99)$ between the groups. There was no difference in the number of attempts for intubation between both the groups (1.48 in SG vs 1.35 in MG, $p=0.146)$. All intubations were done by clinicians of the same expertise. There was no difference in length of PICU stay $(p=0.07)$, between both groups of children.

\section{Discussion}

Limited data was published and no prospective randomized trial could be found in pediatric literature regarding monitoring ETT cuff pressures and their effect on PES. Morbidity secondary to ETT tubes is invariably multifactorial. Adequate ETT cuff pressure is an important factor in deciding the adequacy of mechanical ventilation on one hand and also in preventing airway edema and associated complications on other hand.

The primary aim of our study was to study whether a protocolized endotracheal tube cuff pressure monitoring every 6 hours was a better approach than using bedside clinical assessment in reducing the incidence of post-extubation stridor. Internationally reported incidence of post-extubation stridor is $2-22 \%$ of pediatric intubated patients. ${ }^{3}$ In our study, the rate of post-extubation stridor in the standard group was $8.75 \%$, whereas in the monitoring group it was $6.25 \%(p=0.551)$, thus, we could not find any significant reduction in the incidence of post-extubation stridor in children where a protocolized ETT cuff pressure monitoring was performed every 6 hours. However, Schneider et al., ${ }^{15}$ in their retrospective analysis of a single-center trial showed a significant reduction in the incidence of PES after implementing protocolized ETT cuff leak monitoring. The main difference in our study from their study was that ours was a prospective randomized control study where we primarily maintained a cuff pressure of $20-25 \mathrm{~mm} \mathrm{Hg}$ at every 6 hours interval in the MG, while in SG, the percentage of the leak was monitored and accepted up to $10 \%$ if the child was stable and optimally ventilated. As per our previously existing unit policy, when the ETT leak is more than $10 \%$, we assessed the oxygenation and ventilation of the child, which if acceptable did not change ETT. If either of the parameters has been compromised or if the ETT leak is $>20 \%$, we changed the ETT tube to the next bigger size as appropriate. Schneider et al. ${ }^{15}$ monitored leak around ETT at every 6 hours intervals and accepted leak sound on auscultation at peak inspiratory pressure or cuff pressure of $25 \mathrm{~mm} \mathrm{Hg}$, whichever was higher. In our study, we measured leak around ETT in both groups and found them to be almost the same (5.4\% leak in SG, $4.7 \%$ in MG). Thus, we can assume that if we simply perform a careful assessment of leaks around the ETT by various bedside methodologies as described above, the incidence of PES remained comparable to the protocolized six-hourly ETT cuff pressure monitoring strategy.

Laryngeal edema causing airway obstruction is of variable severity. In severe cases, edema may need emergency reintubation for acute respiratory compromise. ${ }^{19}$ Failed extubation (requiring re-intubation within 48 hours after extubation) is associated with a higher complication rate (increased length of stay in ICU, increased VAP). ${ }^{2,6}$ In our study, the children requiring re-intubation were more in SG $(n=8)$ than MG $(n=2)$, the difference, however, was not statistically significant $(p=0.051)$. Up to half of the pediatric extubation, failures are related to upper airway obstruction (UAO). ${ }^{20}$ Around $15 \%$ of all reintubations are performed due to laryngeal edema developing after extubation in adults. ${ }^{21}$ However, re-intubation due to PES was similar $(p=0.99)$ between both the groups in our study.

We could not find any pediatric literature where VAP rates were analyzed concerning ETT cuff pressure monitoring. In our study, VAP rates were the same in both study groups. In adults, a minimum pressure of $20 \mathrm{~cm} \mathrm{H}_{2} \mathrm{O}$ is recommended for the prevention of VAP. ${ }^{22,23}$ In a study, there was a 4-fold risk for VAP when the ETT cuff pressure was below $20 \mathrm{~cm} \mathrm{H}_{2} \mathrm{O}$ in 83 subjects. ${ }^{24}$ In children, there are no specific recommendations for maintaining cuff pressures. However, in our study, the average cuff pressure in the monitoring group was $21.5 \mathrm{~mm} \mathrm{Hg}$ which is within range as per recommendations. The average duration of mechanical ventilation in both groups was similar. Airway edema can occur shortly after tracheal intubation, and the duration of intubation correlates with the risk of developing laryngeal injury and subsequent PES. ${ }^{25,26}$ Our study has no difference in duration of mechanical ventilation in both groups. In a recently published adult study comparing frequent vs infrequent monitoring of ETT cuff pressures, rates of VAP, ICU, and hospital stay were similar between both study groups. ${ }^{27}$

There are limitations to our study, one of them is that it is a single-center study. This limits the generalizability of our findings. There is very limited data in the published literature which is focused on the actual measurement of cuff pressure in ventilated children. This study provides results that need to be explored in further detail and a much larger population. Secondly, the definition of post-extubation stridor was subjective and it is diagnosed solely by clinical observation. However, this definition was used during the early studies validating the safety and efficacy of using cuffed ETT in children ${ }^{4,5}$ and has been used as an acceptable definition. ${ }^{28}$

\section{ConClusion}

Our study shows that regular bedside assessment of leak around the ETT by "minimal leak" technique and monitoring percentage of the leak around ETT as displayed on the ventilator console is as good as a protocolized measurement and monitoring of ETT cuff 
pressures in terms of preventing post-extubation stridor. Larger multicenter studies may confirm our findings.

\section{ORCID}

Farhan Shaikh (10) https://orcid.org/0000-0001-6160-4930 Yeshwanth Reddy J (i) https://orcid.org/0000-0002-4678-0159 Shashwat Mohanty @ https://orcid.org/0000-0003-1215-7681 Preetham K Reddy (i) https://orcid.org/0000-0003-1711-4197 Kapil Sachane io https://orcid.org/0000-0002-8263-8221 Parag S Dekate @ https://orcid.org/0000-0002-7513-9248 Anupama Yerra (ㄱ https://orcid.org/0000-0002-4383-7578 Dinesh Chirla ㄴ. https://orcid.org/0000-0002-5939-4206

\section{References}

1. Koka BV, Jeon IS, Andre JM, McKay I, Smith RM. Postintubation croup in children. Anesth Analg 1977;56(4):501-505. DOI: 10.1213/00000539197707000-00008.

2. Kurachek SC, Newth CJ, Quasney MW, Rice T, Sachdeva RC, Patel NR, et al. Extubation failure in pediatric intensive care: a multiple-center study of risk factors and outcomes. Crit Care Med 2003;31(11):26572664. DOI: 10.1097/01.CCM.0000094228.90557.85.

3. Tellez DW, Galvis AG, Storgion SA, Amer HN, Hoseyni M, Deakers TW. Dexamethasone in the prevention of postextubation stridor in children. J Pediatr 1991;118(2):289-294. DOI: 10.1016/s00223476(05)80505-0.

4. Deakers TW, Reynolds G, Stretton M, Newth CJ. Cuffed endotracheal tubes in pediatric intensive care. J Pediatr 1994;125(1):57-62. DOl: 10.1016/s0022-3476(94)70121-0.

5. Newth CJL, Rachman B, Patel N, Hammer J. The use of cuffed versus uncuffed endotracheal tubes in pediatric intensive care. J Pediatr 2004;144(3):333-337. DOI: 10.1016/j.jpeds.2003.12.018

6. Edmunds S, Weiss I, Harrison R. Extubation failure in a large pediatric ICU population. Chest 2001;119(3):897-900. DOI: 10.1378/ chest.119.3.897.

7. Zuckerberg AL, Nichols DG. Airway management in pediatric critical care. In: Rogers MC, ed. Textbook of Pediatric Intensive Care, 3rd edition, Maryland: Williams \& Wilkins; 1996. p. 51-76.

8. Thompson AE. Pediatric airway management. In: Fhurman B, Zimmerman JJ, eds. Pediatric Critical Care, 3rd edition, St Louis: Mosby; 2006. p. 492.

9. American Heart Association. Part 12: pediatric advanced life support. Circulation 2005;112(24):IV-167-IV-187. DOI: 10.1161/ CIRCULATIONAHA.105.166573.

10. International Liaison Committee on Resuscitation. The International Liaison Committee on Resuscitation (ILCOR) consensus science with treatment recommendations for pediatric and neonatal patients: pediatric basic and advanced life support. Pediatrics 2006;117(5):e955-e977. DOI: 10.1542/peds.2006-0206.

11. Stauffer JL, Olson DE, Petty TL. Complications and consequences of endotracheal intubation and tracheotomy. A prospective study of 150 critically ill adult patients. Am J Med 1981;70(1):65-76. DOI: 10.1016/0002-9343(81)90413-7.
12. Sengupta P, Sessler DI, Maglinger P, Wells S, Vogt A, Durrani J, et al. Endotracheal tube cuff pressure in three hospitals, and the volume required to produce an appropriate cuff pressure. BMC Anesthesiol 2004;4(1):8. DOI: 10.1186/1471-2253-4-8.

13. Pilbeam SP. Mechanical ventilation: physiological and clinical applications, 6th ed.; 2016. p. 131.

14. Mhanna MJ, Zamel YB, Tichy CM, Super DM. The 'air leak' test around the endotracheal tube, as a predictor of postextubation stridor, is age-dependent in children. Crit Care Med 2002;30(12):2639-2634. DOI: 10.1097/00003246-200212000-00005.

15. Schneider J, Mulale U, Yamout S, Pollard S, Silver P. Impact of monitoring endotracheal tube cuff leak pressure on post extubation stridor in children. J Crit Care 2016;36:173-177. DOI: 10.1016/j.jcrc.2016.06.033.

16. American Heart Association. Pediatric advanced life support provider manual. American Heart Association; 2016. p. 282.

17. Tobias J. Pediatric airway anatomy may not be what we thought: implications for clinical practice and the use of cuffed endotracheal tubes. Paediatr Anaesth 2015;25(1):9-19. DOI: 10.1111/pan.12528.

18. Sultan $\mathrm{P}$, Carvalho B, Rose BO, Cregg R. Endotracheal tube cuff pressure monitoring: a review of the evidence. J Perioper Pract 2011;21(11):379-386. DOI: 10.1177/175045891102101103.

19. Colice G, Stukel T, Dain B. Laryngeal complications of prolonged intubation. Chest 1989;96(4):877-884.

20. Khemani RG, Hotz J, Morzov R, Flink R, Kamerkar A, Ross PA, et al. Evaluating risk factors for pediatric post-extubation upper airway obstruction using a physiology-based tool. Am J Respir Crit Care Med 2016;193(2):198-209. DOI: 10.1164/rccm.201506-1064OC.

21. Epstein SK, Ciubotaru RL. Independent effects of etiology of failure and time to reintubation on outcome for patients failing extubation. Am J Respir Crit Care Med 1998;158(2):489-493. DOI: 10.1164/ ajrccm.158.2.9711045.

22. American Thoracic Society, Infectious Diseases Society of America. Guidelines for the management of adults with hospital-acquired, ventilator-associated, and healthcare-associated pneumonia. Am J Respir Crit Care Med 2005;171(4):388-416. DOI: 10.1164/rccm.200405644ST.

23. Safdar N, Dezfulian C, Collard HR, Saint S. Clinical and economic consequences of ventilator-associated pneumonia: a systematic review. Crit Care Med 2005;33(10):2184-2193. DOI: 10.1097/01. ccm.0000181731.53912.d9.

24. Rello J, Sonora R, Jubert P, Artigas A, Rue M, Valles J. Pneumonia in intubated patients: role of respiratory airway care. Am J Respir Crit Care Med 1996;154(1):111-115. DOI: 10.1164/ajrccm.154.1.8680665.

25. Joshi VV, Mandavia SG, Stern L, Wiglesworth FW. Acute lesions induced by endotracheal intubation. Occurrence in the upper respiratory tract of newborn infants with respiratory distress syndrome. Am J Dis Child 1972;124(5):646-649. DOI: 10.1001/archpedi.1972.02110170024003.

26. Hartley M, Vaughan RS. Problems associated with tracheal extubation. Br J Anaesth 1993;71(4):561-568. DOI: 10.1093/bja/71.4.561.

27. Letvin A, Kremer P, Silver PC, Samih N, Reed-Watts P, Kollef MH. Frequent versus infrequent monitoring of endotracheal tube cuff pressures. Respir Care 2018;63(5):495-501.DOI:10.4187/respcare.05926.

28. Khemani RG, Schneider JB, Morzov R, Markovitz B, Newth CJ. Pediatric upper airway obstruction: Interobserver variability is the road to perdition. J Crit Care 2013;28(4):490-497. DOI: 10.1016/j.jcrc.2012.11.009. 